\title{
Factors Associated with Ball Velocity and Low Back Pain During Kicking in Adolescent Soccer Players
}

This article was published in the following Dove Press journal: Open Access Journal of Sports Medicine

\author{
Michio Tojima ${ }^{1,2}$ \\ Seira Takei $\mathbb{1}^{3}$ \\ Suguru Torii ${ }^{4}$
}

'Waseda Institute for Sport Sciences, Saitama, Japan; ${ }^{2}$ School of Human and Social Sciences, Tokyo International University, Saitama, Japan; ${ }^{3}$ Sensory \& Motor System Medicine, Graduate School of Medicine, The University of Tokyo, Tokyo, Japan; ${ }^{4}$ Faculty of Sport Sciences, Waseda University, Saitama, Japan

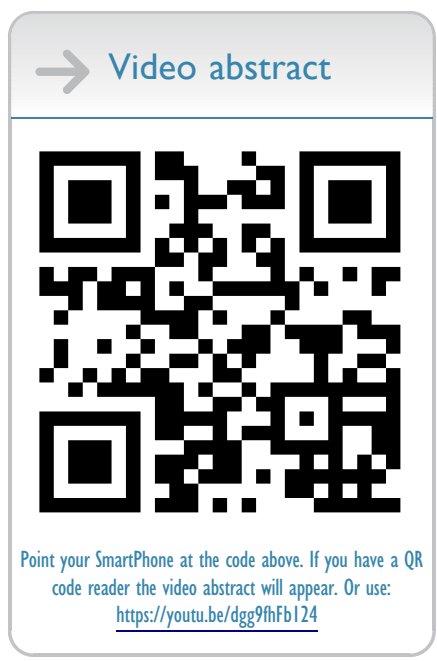

Correspondence: Michio Tojima School of Human and Social Sciences, Tokyo International University, 2509

Matoba, Kawagoe, Saitama 350-II98, Japan

Tel +8I-49-277-5919

Fax +8I-49-232-7477

Email mtojima@tiu.ac.jp
Purpose: The factors associated with low back pain (LBP) and the relationship between LBP and ball velocity during kicking motion of adolescent soccer players remain largely unknown. This study aims to clarify the relationship between increasing ball velocity and LBP in adolescent soccer players.

Participants and Methods: Adolescent soccer players were divided into two groups according to the presence and absence of LBP (LBP group, $n=38$ and NBP (no back pain) group, $n=29$, respectively). Real-time kick motion was measured using a three-dimensional motion analysis system and the angle of the lumbar spine, hip, and center of mass (COM) were calculated. Regression analysis was used to identify factors associated with ball velocity and LBP. In addition, Pearson's correlation coefficients were determined between the angle of the lumbar spine and hip, and ball velocity and position of COM in the extracted phase from regression analysis.

Results: The major factor associated with increasing ball velocity was the rotation angle of both hips (Adjusted $\mathrm{R}^{2}=0.244$ ) and vertical position of COM during kicking (Adjusted $\mathrm{R}^{2}=0.262$ ). Furthermore, the factors associated with LBP were the flexion angle of kickside hip $(\mathrm{OR}=1.126)$ and abduction angle of both hips (kick-side $\mathrm{OR}=1.124$; support-side $\mathrm{OR}=0.872$ ). The factors for ball velocity and LBP were related to the maximum hip extension phase. In the hip extension phase of kicking, compared with the NBP group, the LBP group showed lesser extension and external rotation of the kick-side hip angle. In the hip flexion phase of kicking, the ball velocity was correlated with vertical $(r=0.56) /$ anterior $(\mathrm{r}=0.46)$ position of COM in the NBP group.

Conclusion: To compensate for this restricted hip motion, the LBP group could extend and rotate their lumbar spine, which may likely cause stress to this region.

Keywords: kick motion, low back pain, lumbar spine, hip, adolescent

\section{Introduction}

Many adolescent soccer players experience low back pain (LBP), ${ }^{1,7}$ with LBP being cited as the fourth most common disorder. ${ }^{1}$ Chronic LBP persists for more than 3 months. ${ }^{8}$ The diagnosis and treatment of chronic LBP have been surrounded by debate, and there is no clear consensus on its optimal management. ${ }^{9}$ Moreover, most LBP experienced by soccer players are acute and have identifiable etiologies. Compared with non-athletes, the LBP odds ratio for adolescent soccer players is 1.6-2.0. ${ }^{3}$ Previous studies show a relationship between the presence of lumbar disk degeneration $^{2}$ and/or spondylolysis ${ }^{4}$ and LBP among soccer players. Causative 
factors for LBP, including instability of the trunk muscles, ${ }^{5}$ hip-spine incoordination during movement, ${ }^{6}$ and repetition of excessive lumbar extension and rotation, ${ }^{7}$ have been identified.

Kick movement in adolescent soccer players has been previously reported. ${ }^{10,14}$ When adolescent soccer players kick the ball, they place the support foot near the ball ${ }^{10}$ and rotate the trunk at a high velocity. ${ }^{11}$ Compared with an instep kick, a side-foot kick increases the external rotation angle of the hip, ${ }^{13}$ whereas an outstep kick increases the internal rotation angle of the hip. ${ }^{14}$ During a kicking motion, the presence of LBP laterally shifts the player's center of mass (COM) and considerably rotates the lumbar spine, ${ }^{12}$ which stresses the lumbar spine. A study has reported the relationship between LBP and lumbar movement while kicking. ${ }^{12}$ However, there were no reports on the relationship between LBP and hip-spine incoordination during kicking. The factors associated with LBP and the relationship between LBP and ball velocity during kicking motion of adolescent soccer players remains largely unknown.

Therefore, this study aims to clarify the factors associated with increasing ball velocity and LBP during the kicking motion of adolescent soccer players. We hypothesized that increased rotation of the hip joint during kicking could be associated with faster ball velocity, and increased rotation and extension of the lumbar spine could be associated with an increase in low back pain prevalence. This would be important in preventing LBP in adolescent soccer players.

\section{Materials and Methods}

\section{Participants}

This study was approved by the Office of Research Ethics, Waseda University [\#2016-098], which was conducted in accordance with the Declaration of Helsinki. All participants from a soccer club team provided informed consent. The parents of the participants provided informed consent. We recruited 70 adolescent soccer players from the town recreation league team [age (mean $\pm \mathrm{SD}$ ), 12.6 \pm 0.5 years; height, $156.1 \pm 8.0 \mathrm{~cm}$; body mass, $45.5 \pm 8.2 \mathrm{~kg}$; body mass index, $\left.18.5 \pm 1.9 \mathrm{~kg} / \mathrm{m}^{2}\right]$ in 2018 . Inclusion criteria were as follows: no history of spine/lower limb surgeries and no lower extremity joint pain. These participants attended soccer practice after school and on the weekends, the average time of training/games per week was 5 days, which was supervised by the club team coaches. We excluded the data of three players due to technical difficulty with the measurements.

All participants who developed LBP were assessed by an experienced orthopedist immediately before or after the measurement of kick motion. LBP was assessed and kicking movements were measured on the same day, and the participants did not attend the usual soccer practice. We divided 67 participants into two groups according to the presence and absence of LBP (LBP group, $n=38$; NBP group, $n=29$ ) based on the findings of pain during trunk flexion and trunk extension, Kemp's test, tenderness of the fifth lumbar spinous process, and observations during soccer training, and we asked the participants if LBP had persisted for more than a week. ${ }^{15,16}$ Kemp's test is used to assess the lumbar spine facet joints by having a patient perform extension and rotation of the lumbar spine, with a positive test defined as a reproduction of the patient's pain in the facet joint. ${ }^{16}$ The sensitivity of Kemp's test is $23-100 \%$, and its specificity is $11.6-67.3 \%{ }^{16}$

\section{Motion Analysis}

Half of a basketball court was used for data collection. A regulation soccer ball (FIFA standard) was placed at the center of a circle, which was set at the coordinate center. We placed motion analysis cameras $8.5 \mathrm{~m}$ away from the ball; the accuracy of calibration was set at $1.9 \mathrm{~mm}$. We placed a futsal goal $14 \mathrm{~m}$ ahead of the ball.

The participants warmed up before the measurement and practiced kicking the soccer ball three times. Based on a previous report, ${ }^{12}$ we placed 65 spherical markers on each anatomical landmark and used a combination of three marker placements: Helen Hayes marker for the whole body, ${ }^{17}$ the Point Cluster Technique for the lower legs, ${ }^{18,19}$ and the previous placement technique for the spine. $6,12,20$ To calculate the ball velocity, we attached reflective tapes markers to the ball. We measured the realtime kicking motion using a three-dimensional motion analysis system (Qualisys track manager; Qualisys AB., Sweden) with ten cameras set at $240 \mathrm{~Hz}$ to measure the position of the spherical markers. In the measurement, we asked the participants to kick the ball into the goal, not over the goal height or along the floor. Each participant kicked the ball three times as forcefully as possible. Kick motion and ball velocity data was analyzed from all three kicks. Noise was filtered from the raw data using a $6-\mathrm{Hz}$ low-pass filter.

We used biomechanics analysis software Visual3D v5 (C-Motion, Inc., MD, USA) to calculate the lumbar spine 
angle, hip angle, COM, and maximum ball velocity. We calculated the lumbar spine angle from the thoracolumbar segment with respect to the pelvic segment (ie, the sum of L1-L5 vertebral movements). ${ }^{6}$ Based on previous reports, ${ }^{12,21}$ we collected data related to the following six events (Figure 1): foot contact (FC), toe-off (TO), maximum hip extension (HE), maximum knee flexion (KF), ball impact $(\mathrm{BI})$, and maximum hip flexion (HF).

\section{Statistical Analysis}

The sample size of the $t$-test was calculated using the following formula:

$$
n=2\left(z_{\alpha}+z_{\beta}\right)^{2} *(\sigma / \Delta) 2
$$

where $\mathrm{n}$ indicates the calculated number of participants; the values of $Z_{\alpha}$ and $Z_{\beta}$ are 1.96 and 0.25 , respectively; $\sigma$ indicates the intragroup standard deviation (SD); and $\Delta$ indicates the difference between the means of the LBP and NBP group data (effect size). Alpha $=0.05$ and power $=0.60$ were used to indicate statistical significance. The estimated intragroup $\mathrm{SD}$ was $7^{\circ}$, and the difference of both groups was $4^{\circ}$. With a conservative medium effect size of 0.5 , more than 30 participants were needed for an unpaired $t$-test.

We performed statistical analysis using IBM SPSS Statistics ver. 19.0 (IBM Corp., Endicott, NY). We used stepwise multiple linear regression to identify associations between ball velocity and the angles of the lumbar spine or hip, and COM during kicking. We used logistic regression analysis to identify the factors associated with LBP. Pearson's product-moment correlation coefficients were calculated between factors. To compare the significance between groups (LBP vs NBP), an unpaired $t$-test was used. We calculated the effect size of Cohen's $d$. The level of significance was set at $P<0.05$.

\section{Results}

\section{Factors Associated with Ball Velocity}

Sixty-five players kicked the ball with an instep kick and two players kicked the ball with their inside foot. For the overall group, important factors for increasing ball velocity were greater external rotation of both hips in $\mathrm{HE}$, greater internal rotation of the support-side hip in $\mathrm{HF}$ (Adjusted $\mathrm{R}^{2}=0.244, P<0.001$ ), and larger vertical position of COM in HF (Adjusted $\mathrm{R}^{2}=0.262, P<0.001$, Table 1). In $\mathrm{HF}$, the ball velocity was correlated with vertical (NBP, $\mathrm{r}=0.56, P=0.003$; LBP, $\mathrm{r}=0.46, P=0.002)$ and the anterior (NBP, r=0.46, $P=0.013$; LBP, n.s.) position of $\mathrm{COM}$ in NBP group.

\section{Factors Associated with Low Back Pain}

In the LBP group $(n=38)$, the participants complained about LBP during trunk flexion $(n=4)$, trunk extension $(n=30)$, Kemp's test to the right side $(n=36)$ and left side

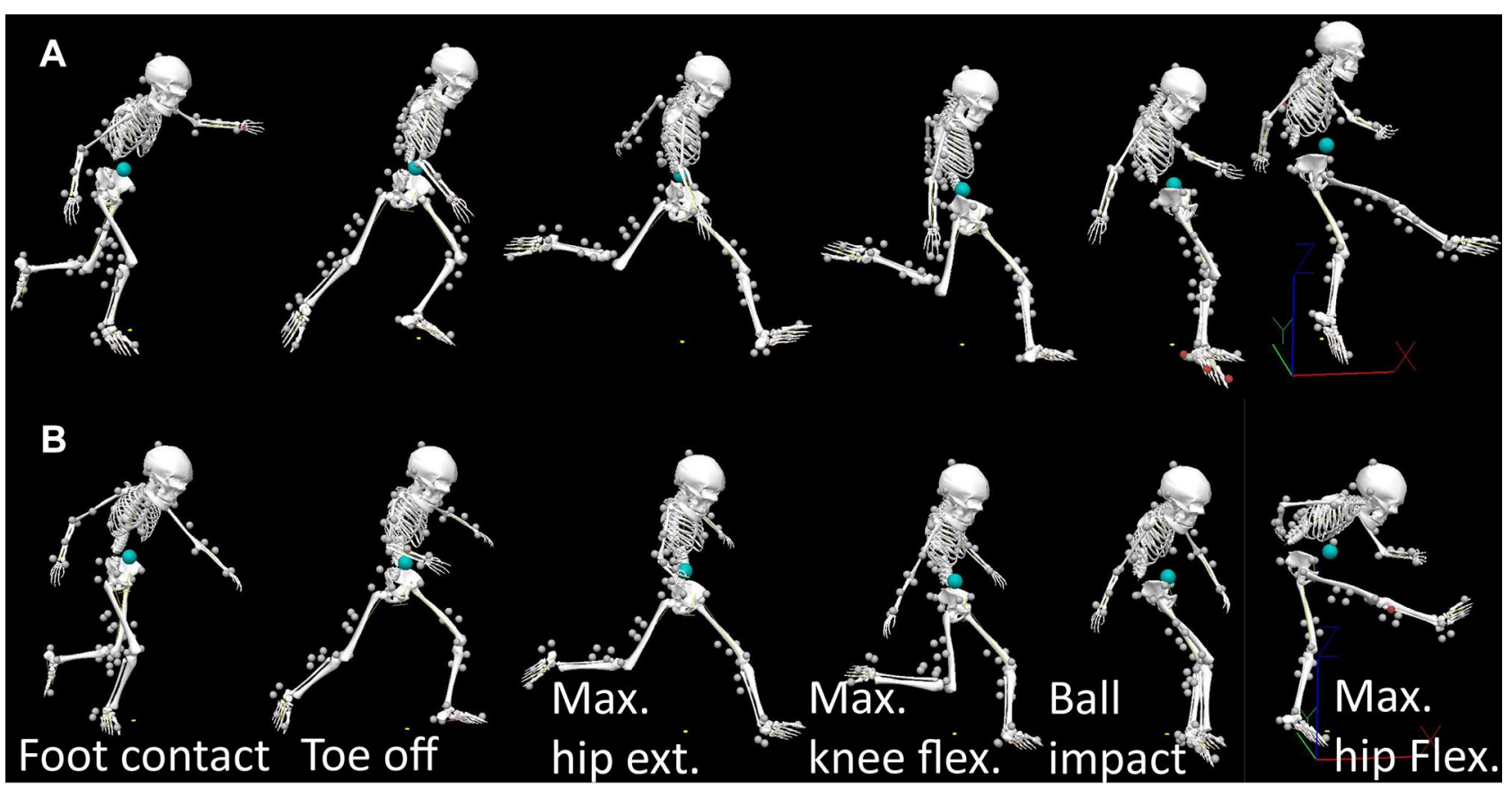

Figure I The kicking motion of adolescent soccer player (A) without and (B) with low back pain. 
Table I Stepwise Multiple Regression Analysis for Ball Velocity

\begin{tabular}{|c|c|c|c|}
\hline \multicolumn{4}{|l|}{ Adjusted $R^{2}=0.244, P<0.00 I$} \\
\hline Model & Unstandardized B & 95\% Confidence Interval & $p$ \\
\hline Constant & 22.554 & $21.290-23.819$ & $<0.001$ \\
\hline Rotation angle of kick side hip in $\mathrm{HE}$ & -0.063 & $-0.119--0.007$ & 0.029 \\
\hline Rotation angle of supported side hip in HE & -0.066 & $-0.116--0.017$ & 0.010 \\
\hline Rotation angle of supported side hip in HF & 0.093 & $0.047-0.139$ & $<0.001$ \\
\hline \multicolumn{4}{|l|}{ Adjusted $\mathrm{R}^{2}=0.262, \mathrm{P} 0.00 \mathrm{I}$} \\
\hline Constant & 12.018 & $7.161-16.876$ & $<0.001$ \\
\hline Vertical position of center of mass $(\mathrm{m})$ in HF & 12.876 & $7.5|1-18.24|$ & $<0.001$ \\
\hline
\end{tabular}

Notes: Increase in absolute value for the positive/negative values of Unstandardized B denotes increasing angles of internal/external rotation and upper/lower position of center of mass, respectively. The significant $P$-values were indicated by boldface type.

Abbreviations: $\mathrm{HE}$, maximum hip extension; HF, maximum hip flexion.

$(\mathrm{n}=33)$, and soccer training $(\mathrm{n}=5)$. In addition, tenderness of the fifth lumbar spinous process was commonly reported $(n=29)$. There were no differences in time spent in each kick phase and the maximum ball velocity between both groups (Table 2). There were no differences of COM position between both groups (Figure 2 and Table 3).

The extracted parameters for the LBP were flexion angle of kick-side hip in $\mathrm{FC}[\mathrm{OR}=1.126,95 \%$ confidence interval (CI) for OR=1.049-1.208, $P=0.001]$ and the abduction angle of both hips in HE (kick-side OR=1.124, 95\% CI for $\mathrm{OR}=1.003-1.260, P=0.045$; support-side $\mathrm{OR}=0.872,95 \%$ CI for OR=0.789-0.965, $P=0.008$, Table 4). Except for the flexion angle of the lumbar spine in $\mathrm{FC}(P=0.039)$ and the tendency of TO $(P=0.078)$, there were no significance differences between groups for lumbar spine angles (Figure 3 and Table 5). Compared with the NBP group, the LBP group showed less extension $(P=0.032)$ and external rotation $(P=0.055)$ on the kick-side hip in HE (Figure 4, Tables 6 and 7). Correlations were found between the restricted extension angle of the kick-side hip and extension angle of the lumbar spine (NBP, $\mathrm{r}=0.345, P=0.066$; LBP, $\mathrm{r}=0.368$, $P=0.023$ ), the abduction angle of the kick-side hip and lateral bending angle of the lumbar spine (NBP, $\mathrm{r}=-0.384, P=0.040$; LBP, $\mathrm{r}=-0.281, P=0.088$ ), and the restricted external rotation angle of the kick-side hip and rotation angle of the lumbar spine to the supported side (NBP, n.s.; LBP, $r=0.344$, $P=0.034)$ in HE (Figure 5).

\section{Discussion}

This study clarifies the factors associated with increasing ball velocity and LBP during kicking motion in adolescent soccer players. The major factor associated with increasing ball

Table 2 Each Parameter of Both Groups

\begin{tabular}{|c|c|c|c|c|c|c|c|}
\hline & \multirow{3}{*}{$\begin{array}{l}\text { NBP Group } \\
\text { Mean } \pm \text { SD }\end{array}$} & \multirow{3}{*}{$\begin{array}{l}\text { LBP Group } \\
\text { Mean士SD }\end{array}$} & \multirow[t]{3}{*}{$\mathbf{P}$} & \multirow{2}{*}{\multicolumn{2}{|c|}{$\begin{array}{l}\text { Tojima et al }{ }^{12} \\
\text { Inside Kick }\end{array}$}} & \multicolumn{2}{|c|}{ Nunome et $\mathrm{al}^{13}$} \\
\hline & & & & & & Instep Kick & Inside Kick \\
\hline & & & & NBP $(n=20)$ & LBP $(n=22)$ & \multicolumn{2}{|c|}{ Toe Off to Ball Impact $(n=5)$} \\
\hline Age (years) & $12.7 \pm 0.6$ & $12.6 \pm 0.5$ & 0.699 & 14.0 & 13.9 & \multicolumn{2}{|c|}{ High school soccer players } \\
\hline Height $(\mathrm{cm})$ & $156.7 \pm 8.6$ & $155.8 \pm 7.9$ & 0.653 & 164.8 & 164.1 & \multicolumn{2}{|c|}{174.6} \\
\hline Weight (kg) & $45.8 \pm 9.0$ & $45.4 \pm 8.0$ & 0.854 & 54.8 & 52.9 & \multicolumn{2}{|l|}{67.6} \\
\hline BMI $\left(\mathrm{kg} / \mathrm{m}^{2}\right)$ & $18.5 \pm 2.2$ & $18.6 \pm 1.8$ & 0.871 & 20.1 & 19.6 & \multicolumn{2}{|l|}{22.2} \\
\hline AP COM distance $(m)$ & $1.62 \pm 0.26$ & $1.57 \pm 0.19$ & 0.451 & - & - & - & - \\
\hline Kick time (s) & $535.1 \pm 94.6$ & $559.9 \pm 77.7$ & 0.243 & 513.6 & 575.2 & 221 & 190 \\
\hline Ball speed $(\mathrm{m} / \mathrm{s})$ & $23.8 \pm 2.4$ & $23.4 \pm 2.3$ & 0.491 & 23.8 & 22.7 & 28 & 23.4 \\
\hline Toe off (\%time) & $26.8 \pm 6.3$ & $28.0 \pm 5.1$ & 0.375 & 26.5 & 27.6 & 0 & 0 \\
\hline Hip extension (\%time) & $44.7 \pm 6.6$ & $44.4 \pm 4.5$ & 0.818 & 40.6 & 42.9 & 48.5 & 33.7 \\
\hline Knee flexion (\%time) & $59.6 \pm 7.1$ & $59.7 \pm 5.2$ & 0.980 & 57.0 & 58.0 & 76.7 & 80 \\
\hline Ball impact (\%time) & $73.6 \pm 8.2$ & $73.1 \pm 7.3$ & 0.801 & 69.6 & 70.5 & 99.9 & 100 \\
\hline
\end{tabular}

Abbreviations: LBP, low back pain; NBP, no low back pain; AP, anterior-posterior. 

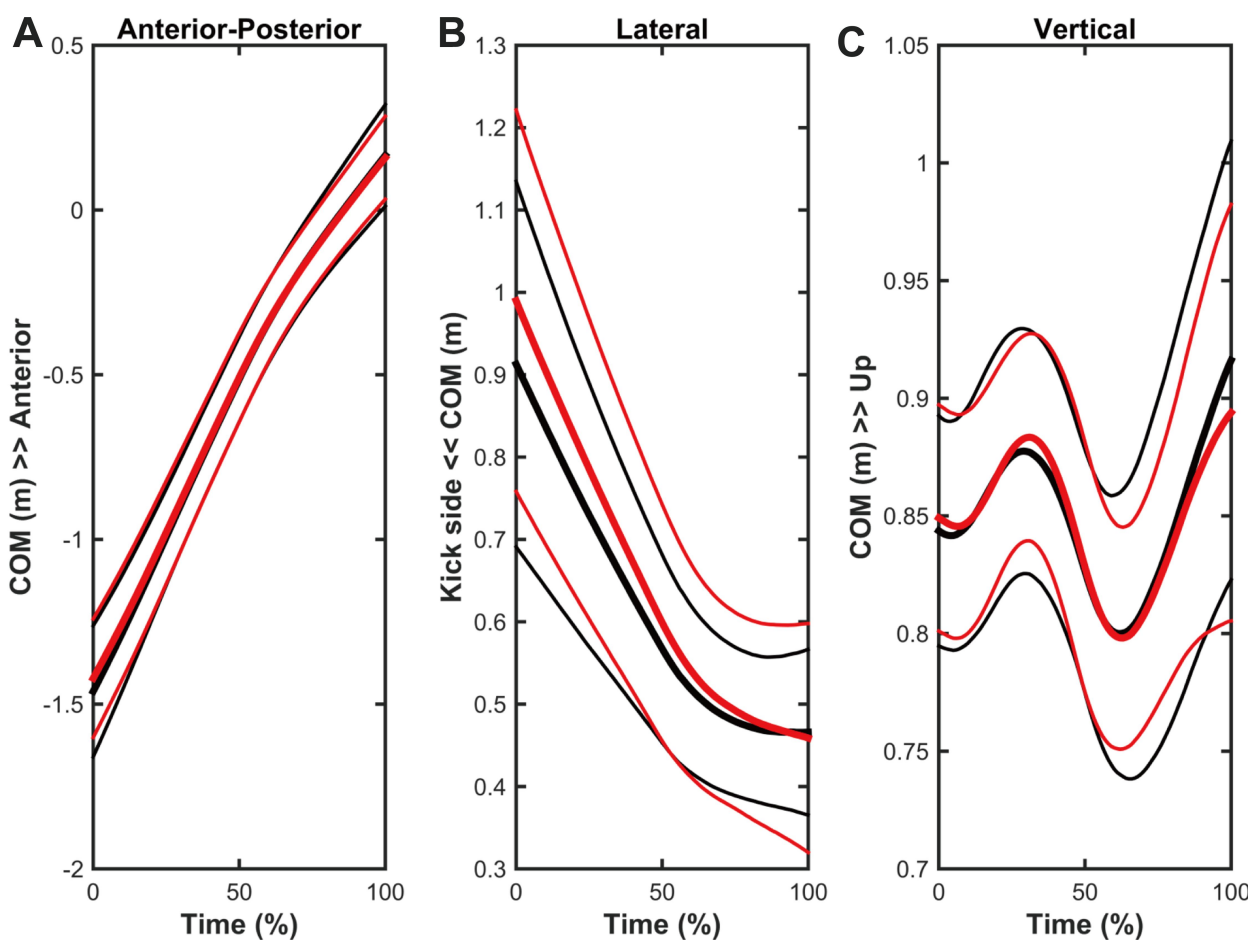

Figure 2 Mean (thick lines) and standard deviation (thin lines) for the center of mass with regard to (A) anterior-posterior, (B) lateral, and (C) vertical. The low back pain group is indicated by red lines and the no low back pain group is indicated by black lines.

velocity was the rotation angle of both hips and vertical position of the COM during kicking. Furthermore, the factors associated with LBP were the flexion angle of the kick-side hip and abduction angle of both hips. The factors associated with ball velocity and LBP were related to the maximum hip extension phase. In the hip extension phase of kicking,

Table 3 The Position of Center of Mass in Both Groups

\begin{tabular}{|c|c|c|c|c|c|c|c|}
\hline & & \multirow{2}{*}{$\begin{array}{l}\text { NBP Group } \\
\text { Mean } \pm S D\end{array}$} & \multirow{2}{*}{$\begin{array}{l}\text { LBP Group } \\
\text { Mean士SD }\end{array}$} & \multirow[t]{2}{*}{$P$} & \multicolumn{2}{|l|}{$95 \% \mathrm{Cl}$} & \multirow[t]{2}{*}{ Cohen's d } \\
\hline & & & & & Lower & Upper & \\
\hline \multirow[t]{6}{*}{ Anterior- Posterior $(\mathrm{m})$} & FC & $-1.46 \pm 0.20$ & $-1.43 \pm 0.18$ & 0.516 & -0.125 & 0.064 & 0.16 \\
\hline & TO & $-0.99 \pm 0.16$ & $-0.94 \pm 0.12$ & 0.168 & -0.049 & 0.035 & 0.35 \\
\hline & $\mathrm{HE}$ & $-0.65 \pm 0.13$ & $-0.63 \pm 0.12$ & 0.599 & -0.077 & 0.045 & 0.13 \\
\hline & $\mathrm{KF}$ & $-0.37 \pm 0.09$ & $-0.36 \pm 0.09$ & 0.449 & -0.017 & 0.023 & 0.19 \\
\hline & $\mathrm{BI}$ & $-0.17 \pm 0.08$ & $-0.17 \pm 0.09$ & 0.849 & 0.004 & 0.022 & -0.05 \\
\hline & $\mathrm{HF}$ & $0.15 \pm 0.15$ & $0.16 \pm 0.14$ & 0.979 & -0.001 & 0.036 & 0.01 \\
\hline \multirow[t]{6}{*}{ Lateral (m) } & FC & $0.92 \pm 0.22$ & $0.98 \pm 0.23$ & 0.266 & -0.064 & 0.057 & 0.28 \\
\hline & TO & $-0.17 \pm 0.17$ & $0.77 \pm 0.16$ & 0.426 & -0.033 & 0.042 & 5.65 \\
\hline & $\mathrm{HE}$ & $0.62 \pm 0.14$ & $0.65 \pm 0.13$ & 0.412 & -0.095 & 0.039 & 0.21 \\
\hline & $\mathrm{KF}$ & $0.53 \pm 0.11$ & $0.55 \pm 0.11$ & 0.426 & -0.023 & 0.028 & 0.20 \\
\hline & $\mathrm{BI}$ & $0.48 \pm 0.10$ & $0.5 I \pm 0.11$ & 0.422 & -0.021 & 0.026 & 0.20 \\
\hline & $\mathrm{HF}$ & $0.46 \pm 0.10$ & $0.47 \pm 0.13$ & 0.972 & -0.001 & 0.030 & 0.01 \\
\hline \multirow[t]{6}{*}{ Vertical (m) } & FC & $0.85 \pm 0.05$ & $0.85 \pm 0.05$ & 0.968 & 0.000 & 0.012 & -0.01 \\
\hline & TO & $0.88 \pm 0.05$ & $0.88 \pm 0.05$ & 0.877 & 0.002 & 0.012 & -0.04 \\
\hline & $\mathrm{HE}$ & $0.86 \pm 0.05$ & $0.86 \pm 0.05$ & 0.906 & 0.001 & 0.012 & -0.03 \\
\hline & $\mathrm{KF}$ & $0.80 \pm 0.05$ & $0.79 \pm 0.05$ & 0.755 & 0.004 & 0.012 & -0.08 \\
\hline & $\mathrm{BI}$ & $0.8 I \pm 0.05$ & $0.8 I \pm 0.05$ & 0.726 & 0.004 & 0.013 & -0.09 \\
\hline & $\mathrm{HF}$ & $0.92 \pm 0.09$ & $0.89 \pm 0.09$ & 0.171 & 0.032 & 0.023 & -0.35 \\
\hline
\end{tabular}

Notes: The positive/negative values denote the anterior/posterior, support/kick-side, and upper/lower position of center of mass, respectively.

Abbreviations: LBP, low back pain group; NBP, no low back pain group; FC, foot contact; TO, toe-off; HE, maximum hip extension; KF, maximum knee flexion; BI, ball impact; $\mathrm{HF}$, maximum hip flexion; $95 \% \mathrm{Cl}, 95 \%$ confidence interval for difference. 
Table 4 The Extracted Parameters for Low Back Pain by Logistic Regression Analysis

\begin{tabular}{|l|l|l|l|}
\hline & OR & $95 \% \mathbf{C l}$ & $P^{*}$ \\
\hline $\begin{array}{l}\text { Flexion angle of the kick-side hip in } \\
\text { FC }\end{array}$ & 1.126 & $1.049-1.208$ & 0.001 \\
$\begin{array}{l}\text { Abduction angle of the kick-side hip } \\
\text { in HE }\end{array}$ & 1.124 & $1.003-1.260$ & 0.045 \\
$\begin{array}{l}\text { Abduction angle of the support-side } \\
\text { hip in HE }\end{array}$ & 0.872 & $0.789-0.965$ & 0.008 \\
\hline
\end{tabular}

Note: *All $P$-values are significant.

Abbreviations: HE, maximum hip extension; FC, foot contact; OR, odds ratio; $95 \% \mathrm{Cl}, 95 \%$ confidence interval for difference.

compared with the NBP group, the LBP group showed lesser extension and external rotation of the kick-side hip angle.

There were no differences between groups in the time spent in each phase of the kick and the maximum ball velocity. Katis and Kellis ${ }^{14}$ measured the kick motion of 10 European adolescent soccer players (mean age, 14 years) and reported that the ball velocity of $19.6 \mathrm{~m} / \mathrm{s}(-16.9 \%$ difference from this study) during an instep kick was faster than that of $18.1 \mathrm{~m} / \mathrm{s}$ ( $-23.3 \%$ difference from this study) during an outstep kick. Nunome et $\mathrm{al}^{13}$ measured the kick motion of Japanese high school soccer players and reported that the ball velocity of
$28.0 \mathrm{~m} / \mathrm{s}$ (18.6\% difference from this study) during an instep kick was faster than that of $23.4 \mathrm{~m} / \mathrm{s}(-0.8 \%$ difference from this study) during an inside kick. Tojima et al $^{12}$ measured the kick motion of Japanese junior high school soccer players and reported that a ball velocity of $23.8 \mathrm{~m} / \mathrm{s}$ in the NBP group (no difference from this study) and $22.7 \mathrm{~m} / \mathrm{s}$ in the LBP group ( $-3.0 \%$ difference from this study) during an inside kick. Our ball velocities were comparable to those found during the inside kick reported by Nunome et $\mathrm{al}^{13}$ and Tojima et $\mathrm{al}^{12}$ (Table 2). Different kicking types and the development and improvement of kicking technique could affect the kick motion and ball velocity.

\section{Factors Associated with Ball Velocity}

In the current study, the important parameters for the increasing ball velocity were larger external rotation angle of both hips in $\mathrm{HE}$ and larger internal rotation angle of the support-side hip in HF. From HE to HF, participants rotated their hips externally to prepare for BI, and then kicked by rotating their support hip internally in HF. This is consistent with the result obtained by Katis and Kellis. ${ }^{14}$ Naito et al ${ }^{11}$ reported that rotation of the trunk with a high velocity increases ball velocity, but did not report on hip rotation.
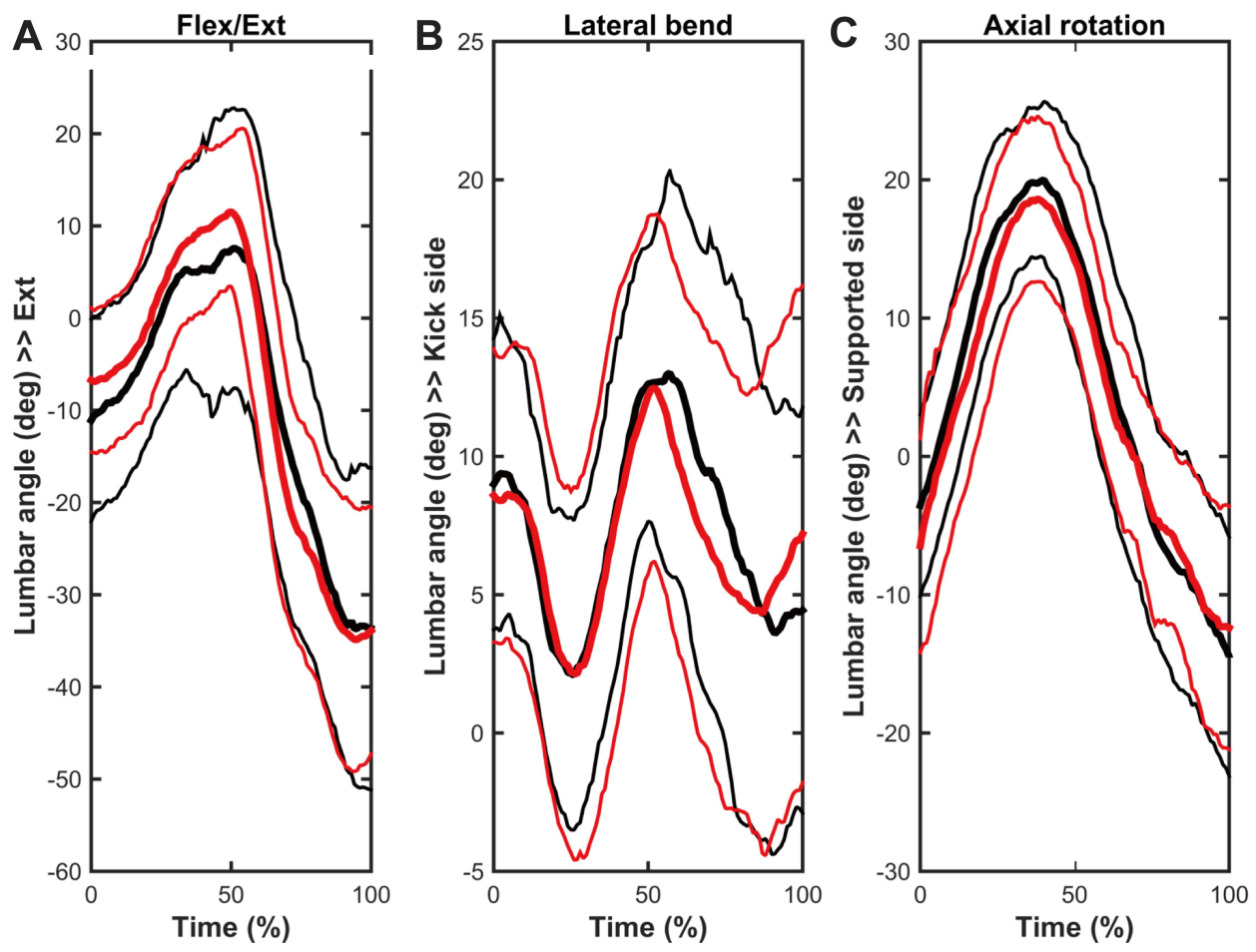

Figure 3 Mean (thick lines) and standard deviation (thin lines) for the angle of the lumbar spine in regard to (A) flexion/extension, (B) lateral bend, and (C) axial rotation. The low back pain group is indicated by red lines and the no low back pain group is indicated by black lines. The positive/negative values denote the extension/flexion, lateral bend to the kick/support-side, and axial rotation to the support-/kick-side, respectively. 
Table 5 The Lumbar Spine Angle of Both Groups

\begin{tabular}{|c|c|c|c|c|c|c|c|}
\hline & & \multirow{2}{*}{$\begin{array}{l}\text { NBP Group } \\
\text { Mean } \pm S D\end{array}$} & \multirow{2}{*}{$\begin{array}{l}\text { LBP Group } \\
\text { Mean } \pm \text { SD }\end{array}$} & \multirow[t]{2}{*}{$P$} & \multicolumn{2}{|l|}{$95 \% \mathrm{Cl}$} & \multirow[t]{2}{*}{ Cohen's d } \\
\hline & & & & & Lower & Upper & \\
\hline \multirow[t]{6}{*}{ Flex/Ext } & FC & $-\mid I . I \pm I I .0$ & $-6.0 \pm 8.0$ & 0.039 & -9.956 & -0.258 & 0.53 \\
\hline & TO & $1.5 \pm 10.4$ & $5.8 \pm 9.0$ & 0.078 & -9.017 & 0.489 & 0.44 \\
\hline & $\mathrm{HE}$ & $6.8 \pm 11.3$ & $9.5 \pm 7.9$ & 0.276 & -7.654 & 2.234 & 0.28 \\
\hline & $\mathrm{KF}$ & $6.2 \pm 14.3$ & $7.2 \pm 11.3$ & 0.765 & -7.170 & 5.296 & 0.07 \\
\hline & $\mathrm{BI}$ & $-20.4 \pm 12.4$ & $-21.1 \pm 11.7$ & 0.823 & -5.259 & 6.589 & -0.06 \\
\hline & $\mathrm{HF}$ & $-33.7 \pm 17.4$ & $-32.5 \pm \mid 4.1$ & 0.767 & -8.833 & 6.544 & 0.07 \\
\hline \multirow[t]{6}{*}{ Lateral bend } & FC & $9.0 \pm 5.3$ & $8.6 \pm 5.3$ & 0.767 & -2.212 & 2.988 & -0.07 \\
\hline & TO & $-20.4 \pm 5.2$ & $1.4 \pm 6.2$ & 0.917 & -2.695 & 2.993 & 3.82 \\
\hline & $\mathrm{HE}$ & II $.0 \pm 4.7$ & $9.7 \pm 6.1$ & 0.335 & -1.349 & 3.898 & -0.24 \\
\hline & $\mathrm{KF}$ & $13.2 \pm 6.2$ & $12.2 \pm 6.3$ & 0.497 & -2.023 & 4.123 & -0.17 \\
\hline & $\mathrm{BI}$ & $9.1 \pm 8.2$ & $7.8 \pm 7.8$ & 0.514 & -2.640 & 5.220 & -0.16 \\
\hline & $\mathrm{HF}$ & $4.3 \pm 7.1$ & $7.1 \pm 9.0$ & 0.174 & -6.818 & 1.257 & 0.34 \\
\hline \multirow[t]{6}{*}{ Rotation } & FC & $-3.5 \pm 6.6$ & $-6.6 \pm 7.9$ & 0.100 & -0.594 & 6.624 & -0.42 \\
\hline & TO & $16.6 \pm 4.7$ & $15.2 \pm 5.2$ & 0.234 & -0.974 & 3.916 & -0.30 \\
\hline & $\mathrm{HE}$ & $20.3 \pm 6.3$ & $18.4 \pm 6.3$ & 0.231 & -1.219 & 4.955 & -0.30 \\
\hline & $\mathrm{KF}$ & $9.5 \pm 6.8$ & $7.5 \pm 5.6$ & 0.198 & -1.063 & 5.023 & -0.32 \\
\hline & $\mathrm{BI}$ & $-1.2 \pm 5.2$ & $-1.7 \pm 6.3$ & 0.737 & -2.395 & 3.370 & -0.08 \\
\hline & $\mathrm{HF}$ & $-13.9 \pm 8.6$ & $-12.1 \pm 9.0$ & 0.408 & -6.148 & 2.531 & 0.21 \\
\hline
\end{tabular}

Notes: The positive/negative values denote the extension/flexion, lateral bend to the kick/support-side, and axial rotation to the support/kick-side, respectively. The significant and tendency of $P$-values were indicated by boldface type.

Abbreviations: LBP, low back pain group; NBP, no low back pain group; FC, foot contact; TO, toe-off; HE, maximum hip extension; KF, maximum knee flexion; BI, ball impact; $\mathrm{HF}$ maximum hip flexion; $95 \% \mathrm{Cl}, 95 \%$ confidence interval for difference.

Importantly, the rotation of both hips through the kick would increase the ball velocity. ${ }^{13,22}$ Furthermore, the follow through to the maximum hip flexion would be important to increase the ball velocity. The COM shifted upward from BI to HF. In the NBP group, there was a correlation between the ball velocity and anterior position of COM, which indicated that the forward shift of COM increased the ball velocity in HF. However, the LBP group did not show a relationship between the ball velocity and anterior position of COM because of LBP.

\section{Factors Associated with Low Back Pain}

The parameters associated with LBP were the flexion angle of kick-side hip in FC. Compared with the NBP group, the LBP group showed a larger flexion angle of the kick-side hip and lesser flexion angle of the lumbar spine in FC. The LBP group would increase the flexion angle of the kick-side hip instead of inhibited lumbar spine motion.

Both the larger abduction angle of the kick-side hip and the smaller abduction angle of the support-side hip in HE were also extracted as parameters for the LBP. In this HE phase, participants abducted both hips and laterally bent the lumbar spine to the kick-side. From FC to BI, the abduction torque peaked ${ }^{23}$ and their loading response would peak, ${ }^{14,22}$ which could stress the lumbar spine. In the HE phase, the abduction angle of the kick-side hip and lateral bending angle of the lumbar spine were correlated in the NBP group only; the LBP group would inhibit the movement of their lumbar spine.

\section{Medical and Athletic Implications}

The movement of the kick-side hip in HE seems important for ball velocity and LBP. Compared with the NBP group, the LBP group showed less extension and external rotation angle of the kick-side hip in this HE phase. The LBP group showed correlations between the restricted extension angle of the kick-side hip and extension angle of the lumbar spine, and the restricted external rotation angle of the kick-side hip and rotation angle of the lumbar spine to the support-side in HE. Compared with the NBP group, the LBP group showed that they extended and rotated their lumbar spine to compensate for the restricted hip motion in HE, likely stressing the lumbar spine. LBP can be caused by excessive lumbar motion relative to the hip, ${ }^{6}$ and repetition of excessive 

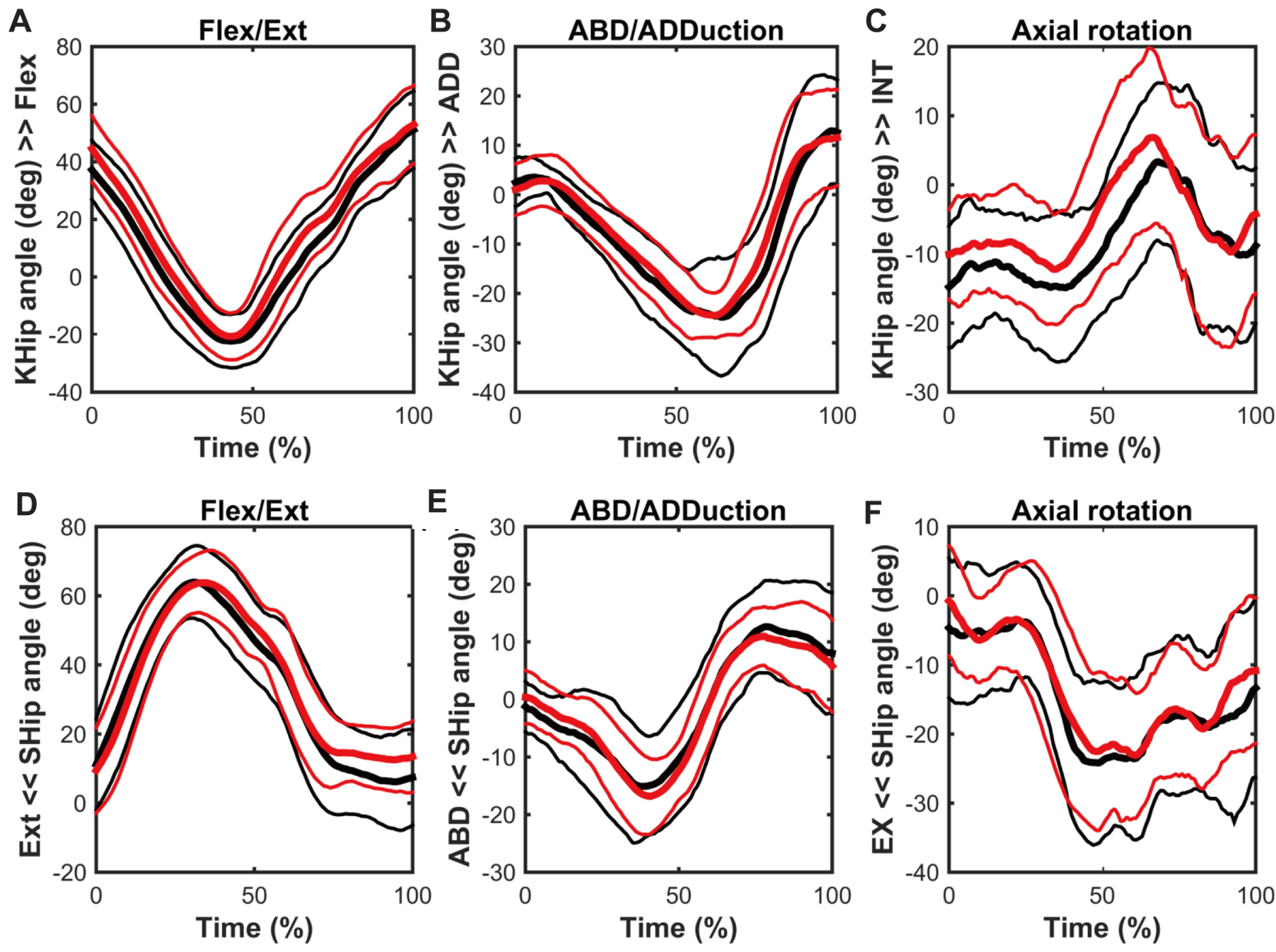

Figure 4 Mean (thick lines) and standard deviation (thin lines) for the angle of both hips in regard to (A and $\mathbf{D})$ flexion/extension, (B and $\mathbf{E})$ abduction/adduction, and $(\mathbf{C}$ and $\mathbf{F})$ axial rotation. The low back pain group is indicated by red lines and the no low back pain group is indicated by black lines. The positive/negative values denote the flexion/extension, adduction/abduction, and internal/external rotation, respectively.

Abbreviations: KHip, kick-side hip; SHip, support-side hip; INT, internal rotation; EX, external rotation.

lumbar extension and rotation. ${ }^{7}$ In this investigation, LBP inhibited lumbar movement in HE; therefore, there were no differences in lumbar movements in HE. The hip motion relative to the lumbar spine, hip-spine coordination, would be important for the prevention of LBP.

Alternatively, the NBP group has not restricted their hip motion relative to the lumbar spine. To increase ball velocity, the follow through to the maximum hip flexion with hip rotation would be important. The hip-spine coordination would be important in increasing ball velocity and preventing LBP. In the future, these factors should be observed longitudinally to predict LBP.

\section{Limitations}

The primary limitation of this study was the selected factors we thought would logically be related to LBP based on our cross-sectional observations. We did not assess the pre/post presence of LBP during kicking. It is necessary to observe the kicking motion longitudinally among adolescent soccer players to clarify the factors associated with LBP and development of kicking technique. In addition, in the definition of LBP, we did not ask whether LBP had persisted for more than 3 months, which is defined as chronic LBP. ${ }^{8}$ In a future study, defining acute or chronic LBP and clarifying the different implications and treatment effects are required.

\section{Conclusions}

This investigation studied the factors associated with increasing ball velocity and LBP during the kicking in adolescent soccer players. To increase the ball velocity, soccer players need to rotate both hips externally in HE and kick through with support-side hip rotation. The factors associated with LBP were the flexion angle of kick-side hip in FC and abduction angle of both hips in HE. In the HE phase of the kick, the LBP 
Table 6 The Kick-Side Hip Angle of Both Groups

\begin{tabular}{|c|c|c|c|c|c|c|c|}
\hline & & \multirow{2}{*}{$\begin{array}{l}\text { NBP Group } \\
\text { Mean士SD }\end{array}$} & \multirow{2}{*}{$\frac{\text { LBP Group }}{\text { Mean } \pm \text { SD }}$} & \multirow[t]{2}{*}{$P$} & \multicolumn{2}{|l|}{$95 \% \mathrm{Cl}$} & \multirow[t]{2}{*}{ Cohen's d } \\
\hline & & & & & lower & upper & \\
\hline \multirow[t]{6}{*}{ Flex/Ext } & FC & $37.2 \pm 10.3$ & $45.1 \pm 10.8$ & $0.003 *$ & -13.127 & -2.719 & 0.75 \\
\hline & TO & $-6.0 \pm 6.1$ & $-3.5 \pm 5.6$ & $0.08 I^{*}$ & -5.416 & 0.327 & 0.43 \\
\hline & $\mathrm{HE}$ & $-26.2 \pm 6.4$ & $-22.4 \pm 7.3$ & $0.032 *$ & -7.169 & -0.328 & 0.54 \\
\hline & $\mathrm{KF}$ & $-4.7 \pm 9.6$ & $0.7 \pm 10.6$ & $0.034^{*}$ & -10.458 & -0.423 & 0.54 \\
\hline & $\mathrm{BI}$ & $14.7 \pm 9.9$ & $19.1 \pm 10.0$ & $0.077^{*}$ & -9.331 & 0.487 & 0.44 \\
\hline & $\mathrm{HF}$ & $50.5 \pm 13.5$ & $52.1 \pm 13.5$ & 0.638 & -8.241 & 5.089 & 0.12 \\
\hline \multirow[t]{6}{*}{ Abduction/Adduction } & FC & $2.5 \pm 4.9$ & $0.9 \pm 5.3$ & 0.220 & -0.960 & 4.102 & -0.31 \\
\hline & TO & $14.7 \pm 3.8$ & $-5.5 \pm 5.3$ & 0.688 & -2.662 & 1.767 & -4.39 \\
\hline & $\mathrm{HE}$ & $-17.6 \pm 6.5$ & $-15.6 \pm 5.9$ & 0.206 & -5.001 & 1.100 & 0.31 \\
\hline & $\mathrm{KF}$ & $-27.4 \pm 5.6$ & $-25.8 \pm 5.1$ & 0.209 & -4.281 & 0.953 & 0.31 \\
\hline & $\mathrm{BI}$ & $-22.5 \pm 5.2$ & $-20.8 \pm 5.4$ & 0.187 & -4.348 & 0.867 & 0.33 \\
\hline & $\mathrm{HF}$ & $12.9 \pm 10.7$ & $10.7 \pm 10.4$ & 0.404 & -3.006 & 7.375 & -0.21 \\
\hline \multirow[t]{6}{*}{ Rotation } & FC & $-14.8 \pm 8.8$ & $-10.1 \pm 6.5$ & $0.016 *$ & -8.398 & -0.908 & 0.60 \\
\hline & TO & $-14.1 \pm 8.5$ & $-11.2 \pm 9.1$ & 0.198 & -7.226 & 1.527 & 0.32 \\
\hline & $\mathrm{HE}$ & $-14.4 \pm 8.6$ & $-10.2 \pm 8.9$ & $0.055^{*}$ & -8.520 & 0.091 & 0.48 \\
\hline & $\mathrm{KF}$ & $-|.8 \pm| 1.3$ & $2.9 \pm 12.0$ & 0.111 & -10.415 & 1.098 & 0.40 \\
\hline & $\mathrm{BI}$ & $5.0 \pm 8.5$ & $5.2 \pm 11.6$ & 0.918 & -5.386 & 4.856 & 0.03 \\
\hline & $\mathrm{HF}$ & $-9.4 \pm \mid 1.5$ & $-4.0 \pm 11.5$ & $0.060 *$ & -11.069 & 0.242 & 0.47 \\
\hline
\end{tabular}

Notes: The positive/negative values denote the flexion/extension, adduction/abduction, and internal/external rotation, respectively. $*$ Significant and tendency of $P$-values. Abbreviations: LBP, low back pain group; NBP, no low back pain group; FC, foot contact; TO, toe-off; HE, maximum hip extension; KF, maximum knee flexion; BI, ball impact; $\mathrm{HF}$, maximum hip flexion; $95 \% \mathrm{Cl}, 95 \%$ confidence interval for difference.

Table 7 The Support-Side Hip Angle of Both Groups

\begin{tabular}{|c|c|c|c|c|c|c|c|}
\hline & & \multirow{2}{*}{$\begin{array}{l}\text { NBP Group } \\
\text { Mean士SD }\end{array}$} & \multirow{2}{*}{$\begin{array}{l}\text { LBP Group } \\
\text { Mean } \pm S D\end{array}$} & \multirow[t]{2}{*}{$P$} & \multicolumn{2}{|l|}{$95 \% \mathrm{Cl}$} & \multirow[t]{2}{*}{ Cohen's d } \\
\hline & & & & & Lower & Upper & \\
\hline \multirow[t]{6}{*}{ Flex/Ext } & $\mathrm{FC}$ & $11.2 \pm 13.2$ & $10.1 \pm 13.7$ & 0.749 & -5.560 & 7.690 & -0.08 \\
\hline & TO & $62.3 \pm 8.7$ & $63.0 \pm 8.4$ & 0.763 & -4.853 & 3.574 & 0.07 \\
\hline & $\mathrm{HE}$ & $55.7 \pm 7.6$ & $59.5 \pm 8.2$ & $0.056^{*}$ & -7.729 & 0.101 & 0.48 \\
\hline & $\mathrm{KF}$ & $42.4 \pm 6.6$ & $46.1 \pm 7.8$ & $0.042 *$ & -7.318 & -0.140 & 0.52 \\
\hline & $\mathrm{BI}$ & $\mid 1.1 \pm 8.3$ & $16.0 \pm 9.3$ & $0.029 *$ & -9.266 & -0.514 & 0.55 \\
\hline & $\mathrm{HF}$ & $7.2 \pm 14.1$ & $14.1 \pm 10.4$ & $0.025^{*}$ & -12.823 & -0.882 & 0.55 \\
\hline \multirow[t]{6}{*}{ Abduction/Adduction } & $\mathrm{FC}$ & $-1.2 \pm 4.4$ & $0.5 \pm 4.6$ & 0.131 & -3.913 & 0.520 & 0.38 \\
\hline & TO & $\mid I . I \pm 8.5$ & $-8.6 \pm 6.5$ & 0.608 & -2.714 & 4.600 & $-2.6 \mathrm{I}$ \\
\hline & $\mathrm{HE}$ & $-16.2 \pm 9.9$ & $-|7| \pm 5.8$. & 0.672 & -3.274 & 5.027 & -0.11 \\
\hline & $\mathrm{KF}$ & $-4.7 \pm 8.2$ & $-4.9 \pm 5.1$ & 0.884 & -3.014 & 3.493 & -0.04 \\
\hline & $\mathrm{BI}$ & $12.0 \pm 6.6$ & $10.8 \pm 4.2$ & 0.392 & -1.606 & 4.021 & -0.22 \\
\hline & $\mathrm{HF}$ & $8.1 \pm 10.5$ & $7.0 \pm 8.1$ & 0.633 & -3.456 & 5.643 & -0.12 \\
\hline \multirow[t]{6}{*}{ Rotation } & $\mathrm{FC}$ & $-4.7 \pm 10.1$ & $-1.3 \pm 9.1$ & 0.162 & -8.022 & 1.372 & 0.35 \\
\hline & TO & $-3.6 \pm 8.7$ & $-3.5 \pm 8.4$ & 0.979 & -4.252 & 4.142 & 0.01 \\
\hline & $\mathrm{HE}$ & $-23.7 \pm 11.2$ & $-21.7 \pm 1 \mid .5$ & 0.473 & -7.640 & 3.586 & 0.18 \\
\hline & $\mathrm{KF}$ & $-22.7 \pm 9.9$ & $-23.9 \pm 7.8$ & 0.573 & -3.084 & 5.526 & -0.14 \\
\hline & $\mathrm{BI}$ & $-16.0 \pm 9.5$ & $-15.2 \pm 8.6$ & 0.705 & -5.266 & 3.583 & 0.09 \\
\hline & $\mathrm{HF}$ & $-13.7 \pm 12.6$ & $-12.2 \pm 12.0$ & 0.628 & -7.524 & 4.572 & 0.12 \\
\hline
\end{tabular}

Notes: The positive/negative values denote the flexion/extension, adduction/abduction, and internal/external rotation, respectively. * Significant and tendency of $P$-values. Abbreviations: LBP, low back pain group; NBP, no low back pain group; FC, foot contact; TO, toe-off; HE, maximum hip extension; KF, maximum knee flexion; BI, ball impact; HF, maximum hip flexion; $95 \% \mathrm{Cl}, 95 \%$ confidence interval for difference. 


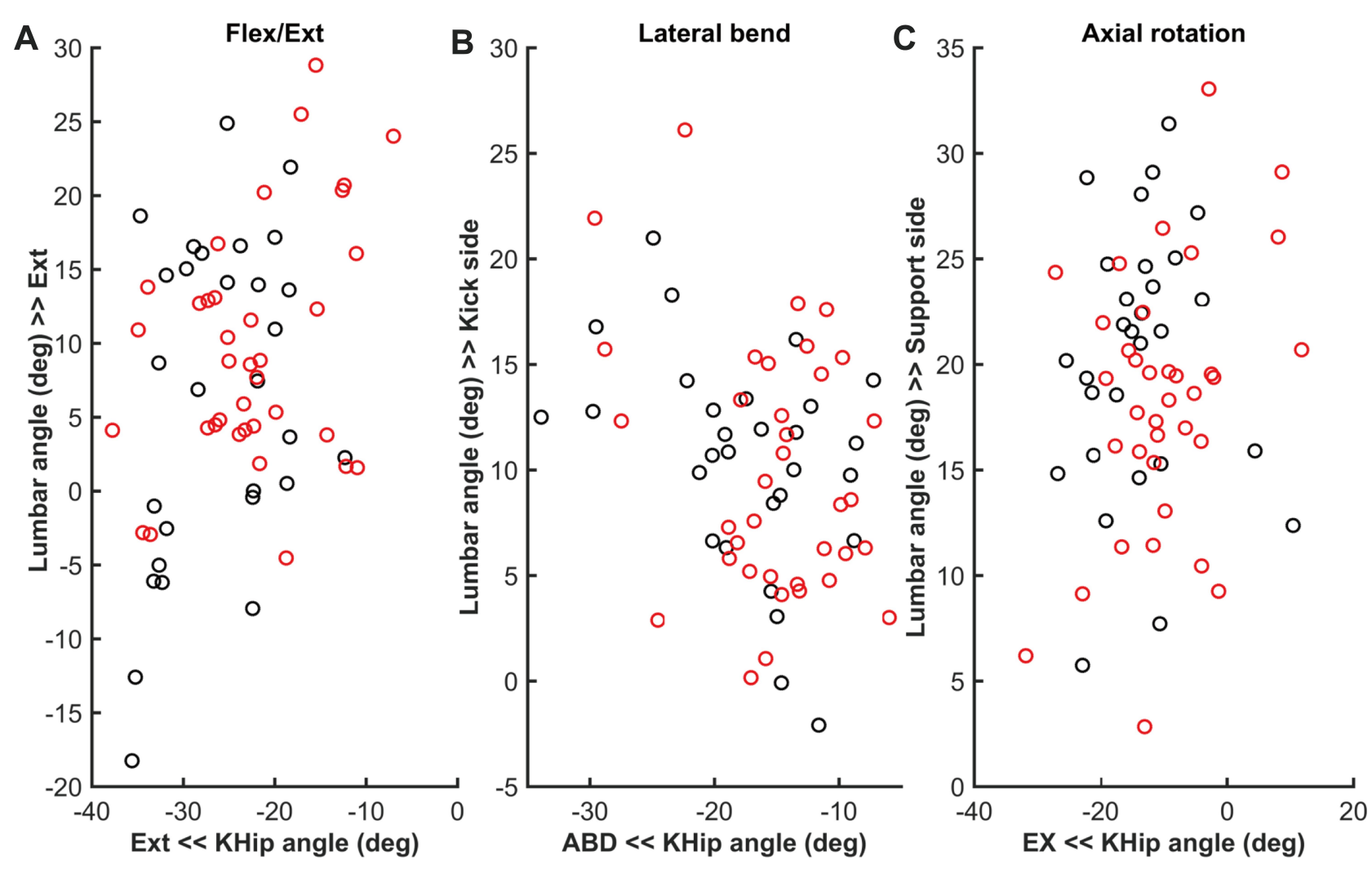

Figure 5 The relationship between the angle of kick-side hip and lumbar spine in the HE phase with regard to (A) sagittal, (B) lateral, and (C) horizontal plane. The low back pain group is indicated by red circles, and the no low back pain group is indicated by black circles. The positive/negative values of the lumbar angle denote the extension/flexion, lateral bend to the kick/support-side, and axial rotation to the support/kick-side, respectively. The positive/negative values of the hip angle denote the flexion/extension, adduction/abduction, and internal/ external rotation, respectively.

Abbreviations: Flex, flexion; Ext, extension; ABD, abduction; EX, external rotation; KHip, kick-side hip; HE, maximum hip extension.

group could extend and rotate their lumbar spine to compensate for the restricted hip motion, which likely put stress on their lumbar spine region and increased ball velocity with hipspine incoordination. Based on these results, hip-spine coordination during kicking is important to increase ball velocity and prevent LBP.

\section{Acknowledgments}

The authors thank Mr. Nao Shinoda at FC GONA and the TORII laboratory staff's assistance with data collection, and Prof. Koji Kaneoka for giving permission to use the 3D motion analysis cameras.

\section{Disclosure}

The authors report no conflicts of interest in this work.

\section{References}

1. Le Gall F, Carling C, Reilly T, Vandewalle H, Church J, Rochcongar P. Incidence of injuries in elite French youth soccer players: a 10-season study. Am J Sports Med. 2006;34(6):928-938. doi:10.1177/036354 6505283271
2. Hangai M, Kaneoka K, Hinotsu S, et al. Lumbar intervertebral disk degeneration in athletes. Am J Sports Med. 2009;37(1):149-155. doi: $10.1177 / 0363546508323252$

3. Sato T, Ito T, Hirano T, et al. Low back pain in childhood and adolescence: assessment of sports activities. Eur Spine J. 2011;20 (1):94-99. doi:10.1007/s00586-010-1485-8

4. Iwamoto J, Abe H, Tsukimura Y, Wakano K. Relationship between radiographic abnormalities of lumbar spine and incidence of low back pain in high school and college football players: a prospective study. Am J Sports Med. 2004;32(3):781-786. doi:10.1177/0363546503261721

5. Hyde J, Stanton WR, Hides JA. Abdominal muscle response to a simulated weight-bearing task by elite Australian rules football players. Human Mov Sci. 2012;31(1):129-138. doi:10.1016/j. humov.2011.04.005

6. Tojima M, Torii S. Changes in lumbopelvic rhythm during trunk extension in adolescent soccer players. Gait Posture. 2017;52:72-75. doi:10.1016/j.gaitpost.2016.11.026

7. Sairyo K, Katoh S, Sasa T, et al. Athletes with unilateral spondylolysis are at risk of stress fracture at the contralateral pedicle and pars interarticularis: a clinical and biomechanical study. Am J Sports Med. 2005;33(4):583-590. doi:10.1177/0363546504269035

8. Mendonça L, Monteiro-Soares M, Azevedo LF. Prediction of clinical outcomes in individuals with chronic low back pain: a protocol for a systematic review with meta-analysis. Syst Rev. 2018;7(1):149. doi:10.1186/s13643-018-0818-2

9. Chapman JR, Norvell DC, Hermsmeyer JT, et al. Evaluating common outcomes for measuring treatment success for chronic low back pain. Spine (Phila Pa 1976). 2011;36(21):S54-68. doi:10.1097/BRS.0b0 13e31822ef74d 
10. Kapidzic A, Huremovic T, Biberovic A. Kinematic analysis of the instep kick in youth soccer players. J Human Kinet. 2014;42:81-90. doi:10.2478/hukin-2014-0063

11. Naito K, Fukui Y, Maruyama T. Multijoint kinetic chain analysis of knee extension during the soccer instep kick. Human Mov Sci. 2010;29(2):259-276. doi:10.1016/j.humov.2009.04.008

12. Tojima M, Torii S. Difference in kick motion of adolescent soccer players in presence and absence of low back pain. Gait Posture. 2017;59:89-92. doi:10.1016/j.gaitpost.2017.10.012

13. Nunome H, Asai T, Ikegami Y, Sakurai S. Three-dimensional kinetic analysis of side-foot and instep soccer kicks. Med Sci Sports Exerc. 2002;34(12):2028-2036. doi:10.1097/00005768-200212000-00025

14. Katis A, Kellis E. Three-dimensional kinematics and ground reaction forces during the instep and outstep soccer kicks in pubertal players. J Sports Sci. 2010;28(11):1233-1241. doi:10.1080/02640414.2010. 504781

15. Sakai T, Sairyo K, Mima S, Yasui N. Significance of magnetic resonance imaging signal change in the pedicle in the management of pediatric lumbar spondylolysis. Spine (Phila Pa 1976). 2010;35 (14):E641-5. doi:10.1097/BRS.0b013e3181c9f2a2

16. Stuber K, Lerede C, Kristmanson K, Sajko S, Bruno P. The diagnostic accuracy of the Kemp's test: a systematic review. J Can Chiropr Assoc. 2014;58(3):258-267.

17. Burnett DR, Campbell-Kyureghyan NH, Topp RV, Quesada PM. Biomechanics of lower limbs during walking among candidates for total knee arthroplasty with and without low back pain. Biomed Res Int. 2015;2015:142562. doi:10.1155/2015/142562
18. Alexander EJ, Andriacchi TP. Correcting for deformation in skin-based marker systems. J Biomech. 2001;34(3):355-361. doi:10.1016/S0021-9290(00)00192-5

19. Cappello A, Cappozzo A, Palombara PFL, Lucchetti L, Leardini A. Multiple anatomical landmark calibration for optimal bone pose estimation. Human Mov Sci. 1997;16(2-3):259-274. doi:10.1016/ S0167-9457(96)00055-3

20. Tojima M, Ogata N, Yozu A, Sumitani M, Haga N. Novel 3-dimensional motion analysis method for measuring the lumbar spine range of motion: repeatability and reliability compared with an electrogoniometer. Spine (Phila Pa 1976). 2013;38(21):E1327-33. doi:10.1097/BRS.0b013e3182a0dbc5

21. Brophy RH, Backus SI, Pansy BS, Lyman S, Williams RJ. Lower extremity muscle activation and alignment during the soccer instep and side-foot kicks. J Orthop Sports Phys Ther. 2007;37(5):260-268. doi:10.2519/jospt.2007.2255

22. Lees A, Asai T, Andersen TB, Nunome H, Sterzing T. The biomechanics of kicking in soccer: a review. J Sports Sci. 2010;28 (8):805-817. doi:10.1080/02640414.2010.481305

23. Clagg SE, Warnock A, Thomas JS. Kinetic analyses of maximal effort soccer kicks in female collegiate athletes. Sports Biomech. 2009;8(2):141-153. doi:10.1080/14763140902752106

\section{Publish your work in this journal}

Open Access Journal of Sports Medicine is an international, peerreviewed, open access journal publishing original research, reports, reviews and commentaries on all areas of sports medicine. The manuscript management system is completely online and includes a very quick and fair peer-review system. Visit http://www.dovepress. com/testimonials.php to read real quotes from published authors. 